\title{
STUDIES ON THE SYNTHESIS AND THE PHYSICOCHEMICAL PROPERTIES OF THIOCHROME PHOSPHATES ${ }^{1}$
}

\author{
WATARU HAMANAKA ${ }^{2}$ \\ Osaka Factory, Sankyo Co., Ltd., Oyodo-ku, Osaka
}

(Received March 17, 1966)

The concentrations of thiamine phosphates are usually determined fluorometrically as thiochrome (Thc) by means of the well-known thiochrome method. In this method, the thiamine phosphates are dephosphorylated and then oxydized to thiochrome which can be extracted from aqueous solution with butanol and determined fluorometrically. The butanol-extraction of The is carried out in order to avoid the interference arising from other concomitant fluorescent materials in aqeous solutions. However, when monochromatic light is used as an exciting light, it may be possible to determine the concentration of The in aqeous phase, because the background fluorescence of coexisting materials in aqueous phase may be decreased in a great measure.

The present investigation was undertaken in order to study the spectral pro. perties of Thc, Thc-MP, and Thc-DP in aqueous solutions.

Although thiochrome triphosphate was previously prepared by Yamamoto (1), the ion-exchange chromatography was not applied for purifing the material. Shnol (2) reported the preparation of some radioactive thiochrome phosphates, but no detail of purification was given.

In this paper, therefore, the preparation of pure materials of Thc, Thc-MP, and Thc-DP and the fluorescence spectra of these compounds in aqueous solutions will be reported.

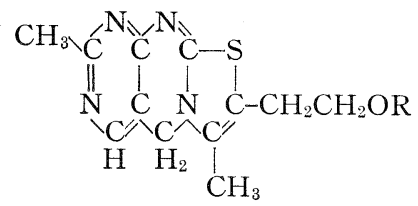<smiles>[R][CH]P(=O)(O)O[Te]P(=O)(O)OP(=O)(O)O</smiles>

\section{EXPERIMENTAL AND RESULTS}

\section{Preparation of Materials}

Thiochrome - The preparation of The followed the process reported by Matsukawa (3). The purification procedure by Utsumi (4) yielded pure Thc, mp 228-229 ${ }^{\circ}$. Elementary analysis. Found: C, 54.64; H, 5.49; N, 21.33. Calculated

\footnotetext{
${ }^{1}$ Following abbreviations are used: The, thiochrome; Thc-MP, thiochrome monophosphate; Thc-DP, thiochrome diphosphate.

2 浜中 涉
} 
for $\mathrm{C}_{12} \mathrm{H}_{14} \mathrm{~N}_{4} \mathrm{OS}: \mathrm{C}, 54.94 ; \mathrm{H}, 5.38 ; \mathrm{N}, 21.36$.

Thiochrome Monophosphate — Ortho-phosphoric acid $(85 \%, 18.5 \mathrm{ml})$ was heated up to $310^{\circ}$ to yield polyphosphoric acid. The $(2.5 \mathrm{~g})$ was added to the polyphosphoric acid cooled to $100^{\circ}$. After two hours' reaction at $100^{\circ}$, the reaction mixture was poured onto a small amount of ice. The resultant aqueous solution was then poured into $600 \mathrm{ml}$ of acetone with stirring leading to a mushy precipitate of thiochrome polyphosphates. The treatment of dissolution in water and precipitation in acetone were repeated once more to remove some free phosphoric acid. The mushy precipitate was dissolved in $20 \mathrm{ml}$ of $6 \mathrm{~N}$ hydrochloric acid and heated to hydrolyze thiochrome polyphosphates to Thc-MP at $60^{\circ}$ for 6 hours. The solution was filtered through carbon. The $\mathrm{pH}$ value of the filtrate was adjusted to 4.0 with concentrated sodium hydroxide. Being kept standing, the solution gave yellow prisms of Thc-MP. The crystals collected by filtration were suspended in $27 \mathrm{ml}$ of water and to this suspension a concentrated sodium hydroxide was added in portion to dissolve the crystals. The resultant solution was acidified to a $\mathrm{pH}$ of 4.0 with concentrated hydrochloric acid. This solution was allowed to stand to give pure Thc-MP, $\mathrm{mp}$ about $260^{\circ}$ (decomposed), weighing $2.0 \mathrm{~g}$. Elementary analysis. Found: C, 36.51; H, 5.44; N, 13.89; P, 7.88; $\mathrm{H}_{2} \mathrm{O}, 13.54$. Calculated for $\mathrm{C}_{12} \mathrm{H}_{15} \mathrm{~N}_{4} \mathrm{O}_{4} \mathrm{PS} \cdot 3 \mathrm{H}_{2} \mathrm{O}: \mathrm{C}, 36.36 ; \mathrm{H}, 5.34 ; \mathrm{N}, 14.14 ; \mathrm{P}, 7.81 ; \mathrm{H}_{2} \mathrm{O}, 13.63$.

Thiochrome Diphosphate — The (7.8 g) was treated with polyphosphoric acid as described above and then with acetone to wash away some free phosphoric acid in a similar manner described above. The aqueous solution of thiochrome polyphosphates was adjusted to $\mathrm{pH} 5.5$ and passed slowly through a column containing $200 \mathrm{ml}(3 \times 28 \mathrm{~cm})$ Dowex $1-\mathrm{X} 8\left(\mathrm{Cl}^{-}\right.$type $)$resin. The adsorbed thiochrome phosphates was eluted with water, $0.01 \mathrm{~N} \mathrm{HCl}$, and $0.025 \mathrm{~N} \mathrm{NaCl}$ in $0.01 \mathrm{~N} \mathrm{HCl}$ successively, giving a chromatogram shown in Fig. 1. The fractions containing

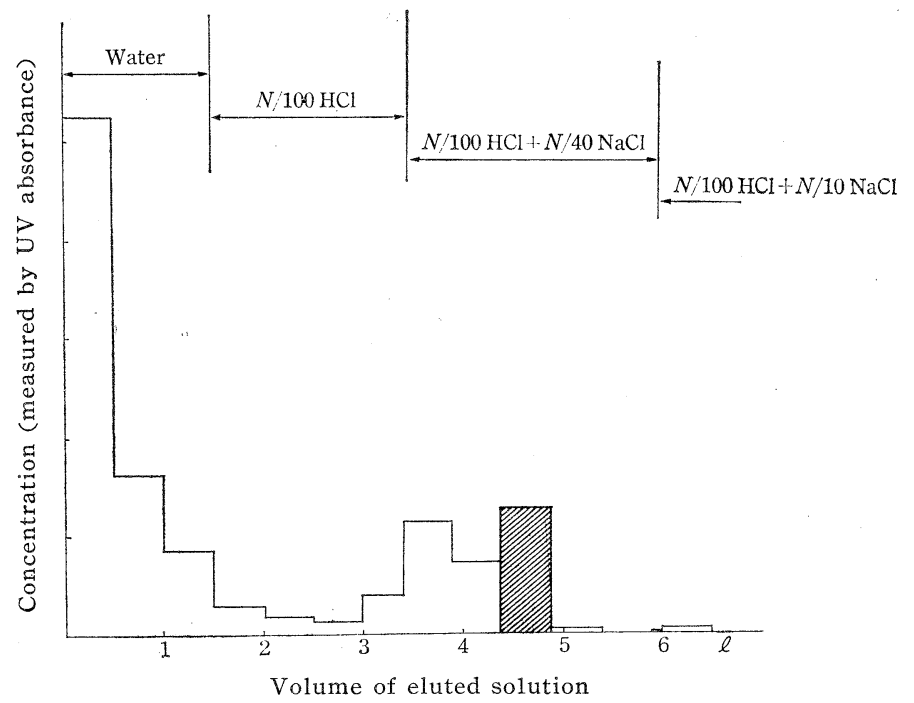

FIG. 1 Separation of Thc-DP by Ion-exchange Resin, Dowex 1-X8 $\left(\mathrm{Cl}^{-}\right.$type), Column Chromatography 
Thc-DP were collected and were concentrated under reduced pressure at room temperature. To this solution, whose $\mathrm{pH}$ value had been adjusted to $6-7$, a concentrated calcium chloride solution was added to precipitate calcium salt of Thc-DP separated from other inorganic salts. One and half grams of this precipitate was suspended in water and dissolved in the solution with addition of sulfuric acid ( $\mathrm{pH}$ 1.2). Precipitated calcium sulfate was collected by filtration and the filtrate was chromatographed over, the ion-exchange resin once more The fractions of Thc-DP were treated with calcium chloride to exclude other inorganic materials and with sulfuric acid to remove the calcium ion as described above. A large amount of acetone was added to the filtrate and the mixture was allowed to stand in a cold place to yield yellow plates of The-DP. The crude crystals were submitted to recrystallization from water by addition of acetone. The yield of pure Thc-DP, mp about $170^{\circ}$ (decomposed), was $0.2 \mathrm{~g}$. Elementary analysis. Found: $\mathrm{C}, 30.57 ; \mathrm{H}, 4.43 ; \mathrm{N}, 11.88 ; \mathrm{P}, 12.90 ; \mathrm{H}_{2} \mathrm{O}, 9.11$. Calculated for $\mathrm{C}_{12} \mathrm{H}_{16} \mathrm{~N}_{4} \mathrm{O}_{7} \mathrm{P}_{2} \mathrm{~S}$ $2.5 \mathrm{H}_{2} \mathrm{O}: \mathrm{C}, 30.83 ; \mathrm{H}, 4.53 ; \mathrm{N}, 11.98 ; \mathrm{P}, 13.25 ; \mathrm{H}_{2} \mathrm{O}, 9.64$.

\section{Paper Chromatography}

A small amount of these compounds $(0.005 \mathrm{ml} \times 1 \mathrm{mg} / \mathrm{ml})$ spotted on a filter paper (Toyo Roshi No. 51A) was developed with a mixture of $1 M$ formate buffer (pH 5.0), isopropanol, and water $(15: 65: 20)$ at $0^{\circ}$ with the descending method. Under irradiation of ultraviolet light, The, Thc-MP, and Thc-DP gave single fluorescent spots at the $R f$ values of $0.37,0.16$ and 0.05 , respectively, showing the purity of these compounds.

\section{Infrared Absorption Spectra}

The infrared absorption spectra of The, Thc-MP, and Thc-DP were recorded in Nujol mull on a Perkin-Elmer infrared spectrophotometer Model 21 and are shown in Fig. 2. The spectrum of The is in good agreement with that reported by Utsumi. The-MP shows strong peaks at 1,170, 1,060, 1,030, 970, and $920 \mathrm{~cm}^{-1}$ and Thc-DP at $1,210,1,110,1,085,1,060,1,010,980$, and $925 \mathrm{~cm}^{-1}$. These peaks can be attributed to the phosphate groups.

\section{Ultravioliet Absorption Spectra}

The ultraviolet absorption spectra of these compounds were recorded at various $\mathrm{pH}$ values with a Beckman automatic recording spectrophotometer Model DK-2. The sample solutions were prepared in $0.01 \mathrm{~N}$ hydrochloric acid (pH 2.1), McIlvain buffer ( $\mathrm{pH} 4.7$ and 7.1), Clark-Lubs buffer ( $\mathrm{pH} 10.0$ ) and $5 \%$ sodium hydroxide ( $\mathrm{pH}$ 13.6). Fig. 3 indicates the spectra of these compounds. These compounds show nearly the same dependence of the spectrum upon $\mathrm{pH}$. In the neutral and alkaline solutions, the absorption maxima are located at $370 \mathrm{~m} \mu$ but by acidification the maxima are shifted to $390 \mathrm{~m} \mu$ accompanied with the appearance of shoulders at about $330 \mathrm{~m} \mu$. This fact means that the light absorption takes place at the thiochrome ring of Thc-MP and Thc-DP and that the phosphorylation of the hydroxyl group scarcely affects electronic structure of the thiochrome group. This seems to be very reasonable because the phosphate group is at a distant part from the conjugated system of the molecules.

\section{Fluorescence Spectra}

The fluorescence and excitation spectra of these compounds were measured with a Shimadzu spectrophotometer model QB-50 equipped with a Shimadzu 
A. The

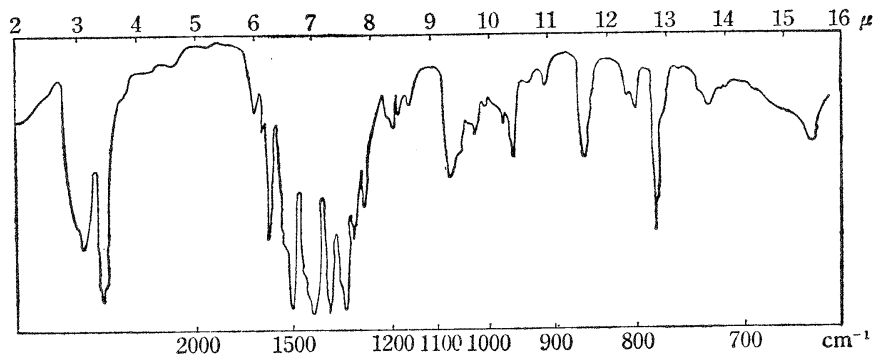

B. Thc-MP

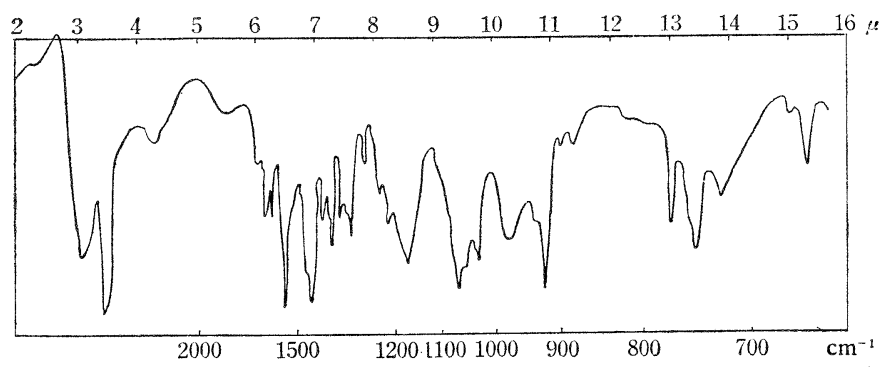

C. The-DP

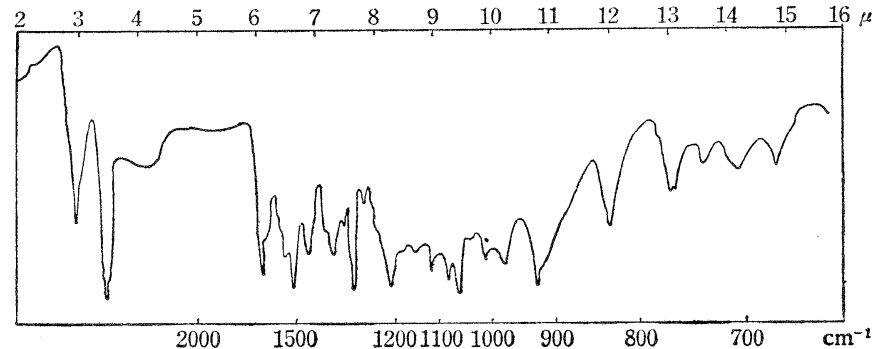

FIG. 2 Infrared Absorption Spectra of Thc Phosphates

TABLE 1

Molecular Extinction Coefficients of The Phosphates at Various pH Levels

\begin{tabular}{|c|c|c|c|c|c|c|}
\hline \multirow{2}{*}{$\mathrm{pH}$} & \multicolumn{2}{|c|}{ The } & \multicolumn{2}{|c|}{ The-MP } & \multicolumn{2}{|c|}{ Thc-DP } \\
\hline & $\lambda_{\max }$ & $\varepsilon$ & $\lambda_{\max }$ & $\varepsilon$ & $\lambda_{\max }$ & $\varepsilon$ \\
\hline & $m \mu$ & & $m \mu$ & & $m \mu$ & \\
\hline 2.1 & 390 & 16,000 & 388 & 14,300 & 383 & 12,000 \\
\hline 4.4 & 390 & 17,400 & 389 & 17,100 & 390 & 16,200 \\
\hline 7.1 & 367 & 20,600 & 367 & 20,900 & 367 & 20,300 \\
\hline 10.0 & 367 & 21,200 & 367 & 21,700 & 367 & 21,300 \\
\hline 13.6 & 367 & 21,300 & 367 & 21,800 & 367 & 20,900 \\
\hline
\end{tabular}


A. The

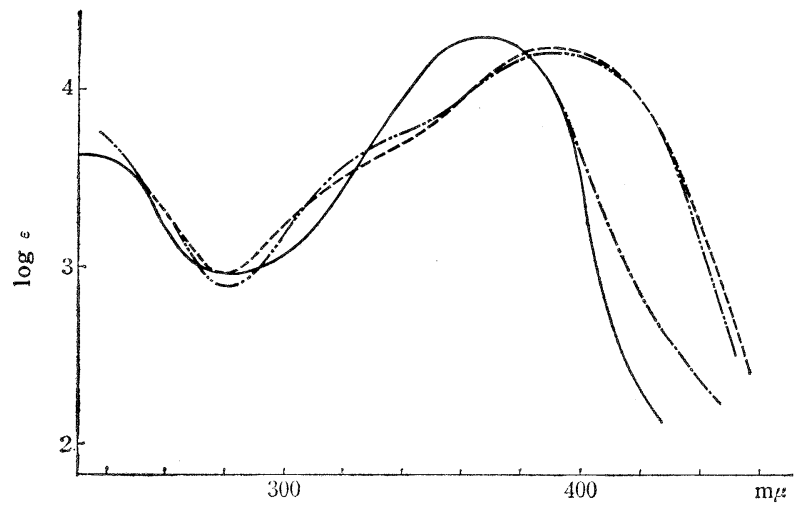

B. Thc-MP

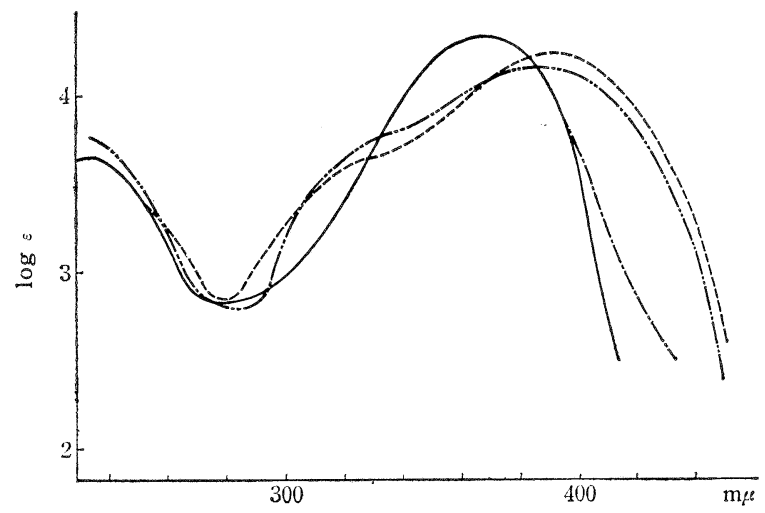

C. The-DP

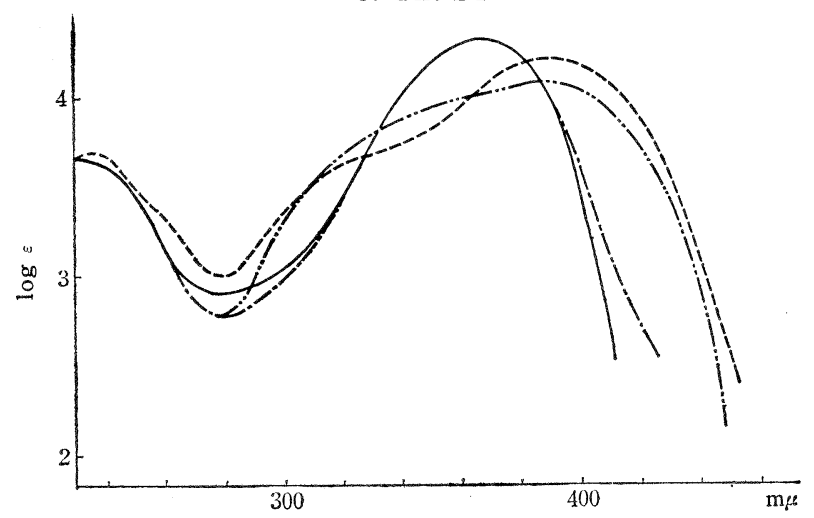

FIG. 3 Ultraviolet Absorption Spectra of The Phosphates at Various pH Levels

$-\cdots, \mathrm{pH}_{2} ; \cdots, \mathrm{pH} 4 ;-\cdot-, \mathrm{pH} 7 ;-, \mathrm{pH} 10$. 
fluorometric accessary Model GF-16. The concentration of these compounds was $4.0 \times 10^{-5} M$ in the acid solutions and $2.0 \times 10^{-5} M$ in the alkaline solutions. The fluorescence spectra of these three compounds are nearly the same as expected from the similarity of their absorption spectra. In the acid medium, the fluorescence spectral maxima of these compounds are located at about $500 \mathrm{~m} \mu$ and the fluorescence intensity is low. In the alkaline medium, on the other hand, strong fluorescence was observed at $450 \mathrm{~m} \mu$. As seen from Fig. 4, the appearance of the fluorescence is scarcely affected by phosphorylation, whereas the quantum yield of the emission is appreciably affected.

The excitation spectra of these compounds dissolved in the alkaline medium $(\mathrm{pH}=10)$ show their peaks at $370 \mathrm{~m} \mu$ where the absorption maxima are located. Therefore, the best condition for the fluorometric determination of The derivatives is exciting the sample solutions with ultraviolet ray of $370 \mathrm{~m} \mu$ and observing the fluorescence at $450 \mathrm{~m} \mu$.

The dependence of the Huorescence of these compounds upon $\mathrm{pH}$ are shown in Fig. 5, indicating that $(a)$ these three compounds fluoresce weakly in the acid

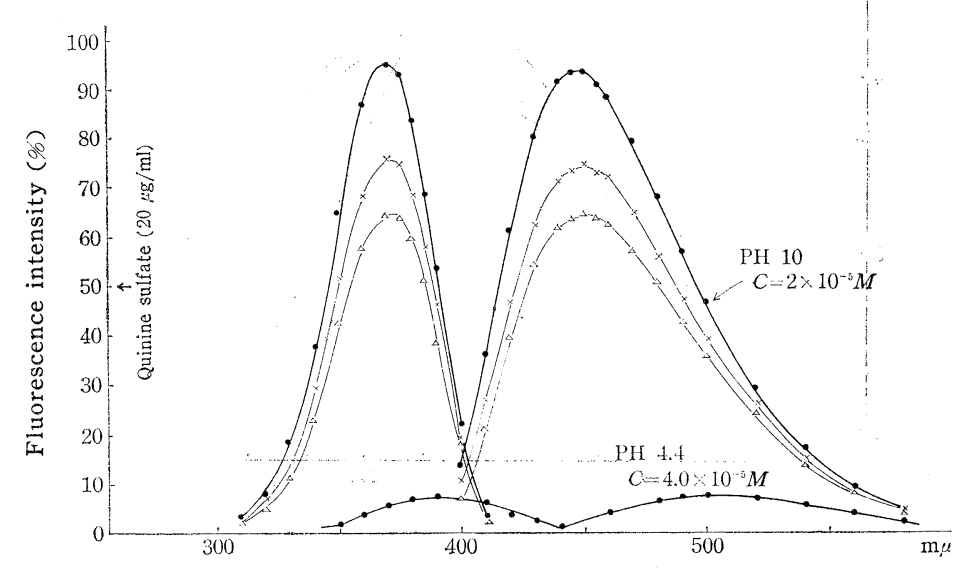

FIG. 4 Excitation and Fluorescence Spectra of The Phdsphates

- The; $\triangle$, The-MP; $\times$, The-DP.

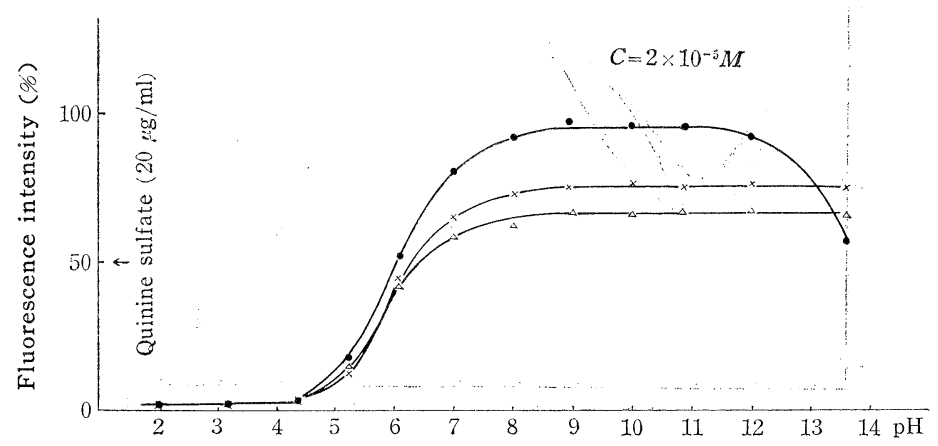

FIG. 5 Relation between the Fluorescence intensities of Thc Phosphates and $p H$

-, The; $\triangle$, Thc-MP; $\times$, The-DP. 
but strong in the alkaline medium and $(b)$ the fluorescence intensity of these compounds are constant over the range of $\mathrm{pH} 9$ to 12 with the order of intensity, The $>$ Thc-DP $>$ The-MP, but $(c)$ the intensity of The is markedly weakened over $\mathrm{pH}$ 13.6.

\section{Calibration Curves}

Fig. 6 shows the relationship between the fluorescence and the concentration of these compounds. The straight calibration curves (solid lines in Fig. 6) were obtained by carrying out the analysis of variance of experimental values with 3 levels and 5 replications of each sample. From this results it was concluded that the ratio of fluorescence intensity is 10:8:9 for The: The-MP: Thc-DP. It is of interest to note that monophosphate group quenches the fluorescence emission of the molecules but diphosphate group recovers it partly.

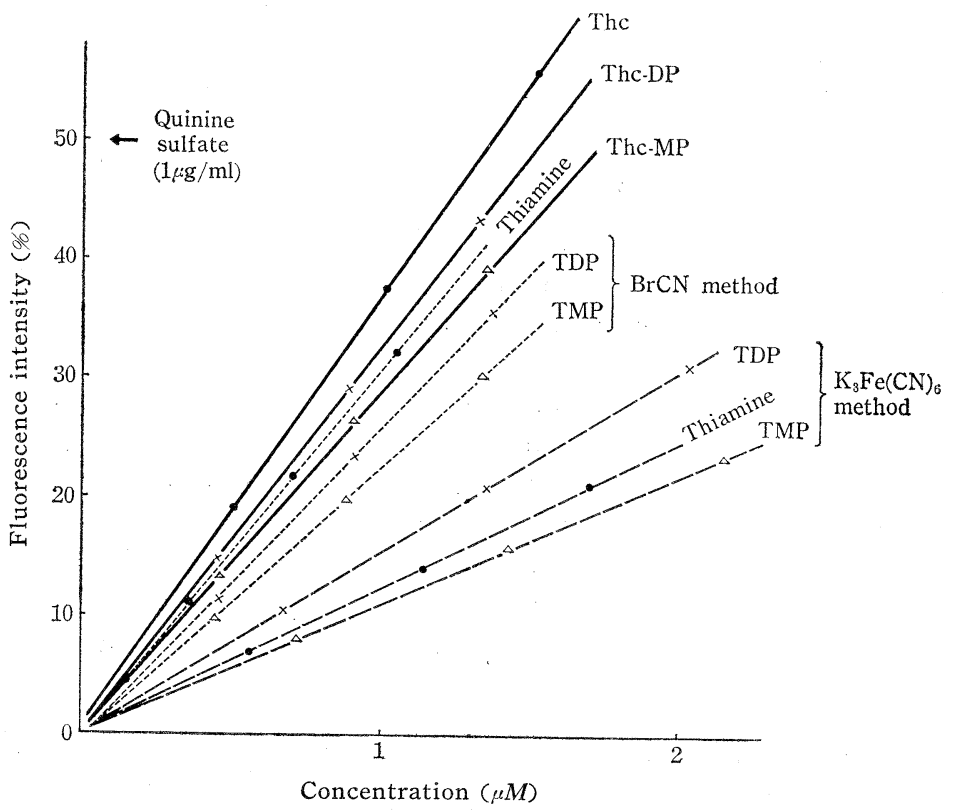

FIG. 6 Calibration Curvs of The Phosphates and Thiamine Phosphates

\section{Fluorescence Intensity of Thiochrome Phosphates Derived from Thiamine} Phosphates

The dependence of fluorescence intensity upon the concentration was also studied for Thc, Thc-MP, and Thc-DP derived from thiamine, thiamine monophosphate (TMP), and thiamine diphosphate (TDP) respectively. Dilute solutions (2 to $\left.8 \times 10^{-6} \mathrm{M}\right)$ of thiamine hydrochloride, TMP phosphate and TDP chloride were treated with cyanogen bromide and potassium ferricyanide according the procedure shown in Table 2. Measurements of fluorescence intensity were carried out directly on the reaction mixture (Fig. 6). When cyanogen bromide was used as an oxidizing agent, a reasonable result was obtained considering the reaction yields. 
On the other hand, when potassium ferricyanide was used, the fluorescence intensities are about a half of pure The, Thc-MP and Thc-DP. In addition, the order of fluorescence intensity is different from that obtained in section 6 . In this case, therefore, cyanogen bromide is preferable to potassium ferricyanide as an oxidizing agent.

TABLE 2

The Analytical Procedure of Thiamine Phosphates without Dephosphorylation

\begin{tabular}{|c|c|c|c|}
\hline Cyanogen bromide method & \multicolumn{3}{|c|}{ Potassium ferricyanide method } \\
\hline $\begin{array}{l}\text { 1. Sample solution } \\
\left(2 \text { to } 8 \times 10^{-6} M, \mathrm{pH} 4.5\right)\end{array}$ & $3.0 \mathrm{ml}$ & $\begin{array}{l}\text { 1. Sampl solution } \\
\left.\text { ( } 2 \text { to } 8 \times 10^{-6} M, \mathrm{pH} 4.5\right)\end{array}$ & $3.0 \mathrm{ml}$ \\
\hline $\begin{array}{l}\text { 2. Add BrCN solution } \\
\text { Shake for } 30 \text { sec. }\end{array}$ & $6.0 \mathrm{ml}$ & 2. $\operatorname{Add}\left\{\begin{array}{ccc}1 \% \mathrm{~K}_{3} \mathrm{Fe}(\mathrm{CN})_{6} & 1 \mathrm{ml} \\
+ & \end{array}\right\}$ & $4.0 \mathrm{ml}$ \\
\hline $\begin{array}{l}\text { 3. Add } 15 \% \mathrm{NaOH} \\
\text { Shake for } 30 \mathrm{sec} \text {. and keep } \\
\text { standing for } 10 \mathrm{~min} \text {. }\end{array}$ & $4.0 \mathrm{ml}$ & $\begin{array}{l}{[15 \% \mathrm{NaOH} \quad 29 \mathrm{ml}]} \\
\text { Shake for } 30 \mathrm{sec} \text {. and keep } \\
\text { standing for } 10 \mathrm{~min}\end{array}$ & \\
\hline $\begin{array}{l}\text { 4. Add } 10 \% \mathrm{H}_{3} \mathrm{PO}_{4} \\
(\mathrm{pH} 10 \text { to } 11)\end{array}$ & $4.0 \mathrm{ml}$ & $\begin{array}{l}\text { 3. Add } 10 \% \mathrm{H}_{3} \mathrm{PO}_{4} \\
(\mathrm{pH} 10 \text { to } 11)\end{array}$ & $4.5 \mathrm{ml}$ \\
\hline 5. Measure the fluorescence int & ity & 4. Measure the fluorescence in & sity \\
\hline
\end{tabular}

The effect of potassium ferricyanide on the fluorescence intensity of thiochrome phosphates studied in order to understand the fact described above. Measurements was made of the $\mathrm{pH} 10$ buffer solution containing $1 \times 10^{-6} \mathrm{M}$ of thiochrome phosphates and potassium ferricyanide of the same concentrations with analytical procedure described in Table 2. As indicated in Table 3, the presence of potassium ferricyanide quenches the emission of thiochrome phosphates to a great extent. The shift of fluorescence maxima was also observed $(450 \rightarrow 460 \mathrm{~m} \mu)$. The depression of fluorescence intensity and the wavelength shift of fluorescence maxima are due to a quenching effect of potassium ferricyanide showing a absorption maximum at near $420 \mathrm{~m} \mu$. The cause of the quenching effect is likely due to the absorption by potassium ferricyanide of a part of fluorescence of The derivatives.

TABLE 3

Quenching Effect of Potassium Ferricyanide on the Fluorescence Intensity of The Phosphates (concentration $=1 \times 10^{-6} \mathrm{M}$ )

\begin{tabular}{lccc}
\hline \multirow{2}{*}{ Compound } & \multicolumn{2}{c}{ Fluorescence intensity } & Quenching \\
\cline { 2 - 3 } & $\begin{array}{c}\mathrm{pH} 10 \text { buffer } \\
\text { solution }\end{array}$ & $\begin{array}{c}\mathrm{pH} \text { 10 buffer soln. } \\
\text { containing } \mathrm{K}_{4} \mathrm{Fe}(\mathrm{CN})_{6}\end{array}$ & per cent \\
& \multicolumn{3}{c}{ per cent } \\
Thc & 36.2 & 16.7 & 53.6 \\
Thc-Mp & 28.0 & 14.0 & 50.0 \\
Thc-DP & 32.0 & 16.7 & 47.8 \\
\hline
\end{tabular}

The fluorescence intensity of $1 \mu \mathrm{g} / \mathrm{ml}$ quinine sulfate solution was taken as $50 \%$.

\section{SUMMARY}

Thiochrome, its mono- and diphosphate were synthesized and their physicochemical properties such as paper chromatography, ultraviolet absorption, infrared absorption and fluorescnce spectra were investigated. It was found that the ultraviolet 
absorption and fluorescence maxima of these compounds were shifted to longer wavelengths with decreasing $\mathrm{pH}$ values. In alkaline solutions, the ultraviolet absorption and fluorescence maxima are located at 370 and $450 \mathrm{~m} \mu$, respectively. It is of interest to note that the phosphorylation induces no changes in the absorption and the appearance of emission spectra but induces an appreciable decrease in the fluorescence intensity. The ratio of the fluorescence intensity, thiochrome: thiochrome monophosphate: thiochrome diphosphate, is 10:8:9 in the alkaline solution ( $\mathrm{pH} 9$ to 12 ).

The concentration of thiamine, thiamine monophosphate, and thiamine diphosphate were determined fluorometrically without dephosphorylation. A reasonable results was obtained when cyanogen bromide was used as an oxidizing agent, whereas an unreasonable result was obtained when potassium ferricyanide was used because of its quenching effect.

\section{ACKNOWLEDGEMENT}

The author would like to express his sincere thanks to Dr. Munetoshi Matsui and Dr. Akira Ito for their encouragement throughout this investigation.

\section{REFERENCES}

1. Yamamoto, K., Vitamines 6, 900 (1953).

2. Shnol, S. E., Byull. Eksptl. Biol. Med. 39, 72 (1955).

3. Matsukawa, T., and Iwatsu, T., Yakugaku Zasshi 70, 28 (1950).

4. Utsumi, I., and Harada, K., Vitamines 26, 123 (1962). 